\title{
Sensory Drawing Data
}

\author{
Esther Rolinson \\ Rolinson Craig Ltd \\ Hastings, UK \\ info@estherrolinson.co.uk
}

\author{
Sean Clark \\ Interact Digital Arts Ltd \\ Leicester, UK \\ seanc@interactdigitalarts.uk
}

\begin{abstract}
Sensory Drawing Data reflects on a collaborative research project between Esther Rolinson and Sean Clark. It focuses on the use of computational processes to identify underlying structures and behaviours in Esther Rolinson's drawings. The purpose of this is to define a movement language that can be used to control lights in Rolinson's installation artworks. In this stage the work has a direct relationship to a series of public art works that Rolinson is currently developing in her role as Lead Artist for the building of a new surgical building for Musgrove Park Hospital, Taunton. It informs Rolinson and Clark's shared curiosity about the structures embedded in human actions and sensations. It explores connections between handmade/human and digital processes of construction.
\end{abstract}

Art. Computer art. Digital art. Public art. Systems.

\section{INTRODUCTION}

Sensory Drawing Data is a collaborative research process currently underway between Esther Rolinson and Sean Clark that builds on earlier collaborations (Rolinson and Clark, 2016; 2018a; Clark and Rolinson, 2017). It focuses on the use of data derived from drawings and sketches made by Rolinson for a series of systems-based artworks and architectural interventions planned in her role as the lead artist for the development of a Surgical Centre at Musgrove Park Hospital, Taunton. When completed, the Musgrove Park artworks will include a major installation and a series of smaller works, lighting and way-finding schemes.

The body of artworks in development will take a variety forms, materials and technologies and extend throughout the Surgical Centre buildings and landscape design. In the project a primary artwork will be developed and incorporated into the fabric of the building or embedded as a standalone structure. The principles of this work will be the basis for a network of smaller artworks and design features/interventions. To make the work, Rolinson is evolving a visual language through a drawing process.

\section{EXPLORATION OF THE DRAWING PROCESS}

The process starts with 'pencil and paper' style drawings made by Esther Rolinson. Once potentially interesting creative directions have been identified, Rolinson uses a digital drawing tool developed by Clark to reproduce selected drawings. This generates drawing data for use in subsequent analysis. Drawing data consists of time-stamped vectors and control commands (such as a change of pen colour) that allow the drawings to be replayed in real-time.

One of Rolinson and Clark's goals is to identify patterns of movement in the original drawings that can be the basis of a movement language used to control of lighting effects.

Time-based and spatial analysis of the digital drawings has revealed that there are clear rhythmic patterns in Rolinson's drawings and that these can be described sequentially. In our terminology drawings consist of multiple marks and these in turn consist of segments. In order to inspect these elements in detail, Clark has extended the digital drawing tool to not only record mark-making, but to replay them and highlight their parts.

The analysis of the drawing data has so far been largely based around the identification of curves and lines produced within the drawings. Using timebased rules, similar to those used by Clark and Scrivener (1993), it has proven possible to deconstruct Rolinson's drawings into their constituent marks and segments with a high degree of accuracy.

Once deconstructed, the resulting drawing elements are then used to control the fading and animation of light sequences. The result is a set of lighting sequences that have direct correlations 
with the original drawings and, although expressed differently, share rhythms and patterns.

Significant numbers of drawing have been captured through the digital drawing tool. The first stage in the use of this data was to use it to create a series of rhythms that have been used experimentally in Rolinson's light works. Shown here in the prototype artworks Ignite (Figure 1) and Revolve (Figure 2).

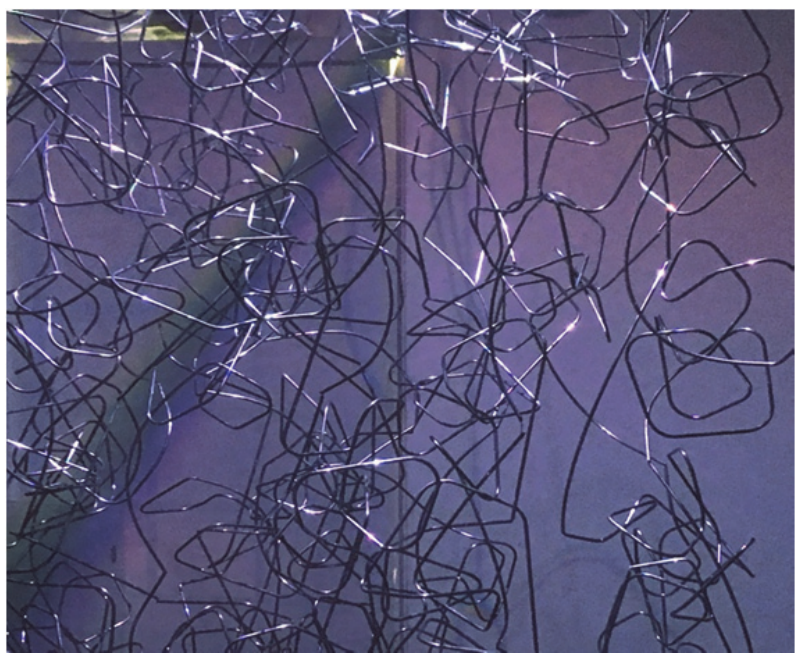

Figure 1: 'Ignite' Light Installation detail by Esther Rolinson programming developed in collaboration with Sean Clark.

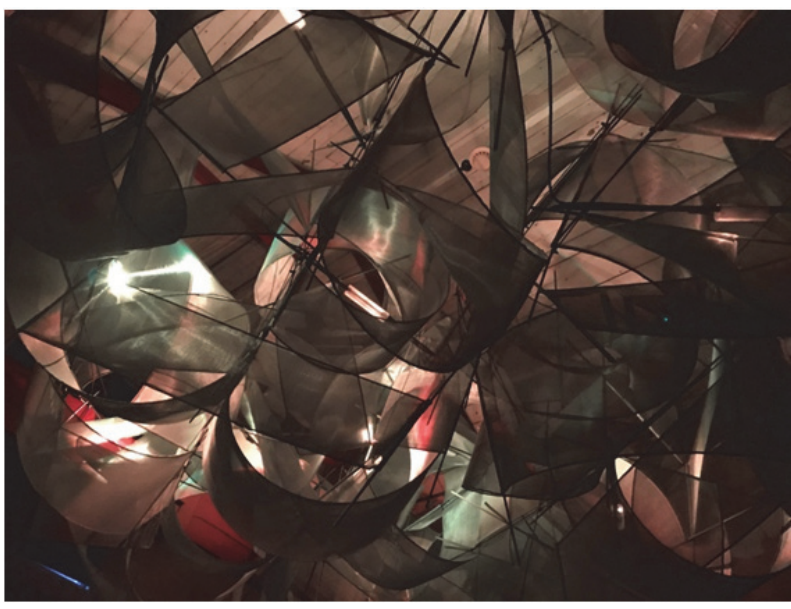

Figure 2: 'Revolve' Light Installation by Esther Rolinson programming developed in collaboration with Sean Clark.

In these examples the drawing marks and segments from the drawings are used to denote an incline to full brightness of light, a sustain period and a dissolve. Each light node plays out its aspect of the drawing until completed. As it executes, the playback program looks for the available light to replay the next line of drawing data. This is a similar process to Rolinson's drawing technique in which she looks for the available space to extend structures into, allowing the overall form to build up through the process. The result is simple but unpredictable, as the patterns gradually become increasingly intertwined as the playback program seeks the next available light.

\section{THE DRAWING MACHINE}

The rhythms and patterns of the drawing structures have also been explored through a digital drawing process. Using a small drawing machine, Rolinson and Clark devised an experimental process called 'Drawing Game'. In it, the rules of a repetitive shape (such as those in Figure 4) were described for another person to replicate. As the person drew with the drawing tool, the drawing machine produced a live copy. This soon revealed that the rules of a given shape are in fact complex and require practice to execute, but they can become a fluid movement. This work was shown at the V\&A Digital Futures 2018 Exhibition that focused on Artificial Intelligence (2018b).

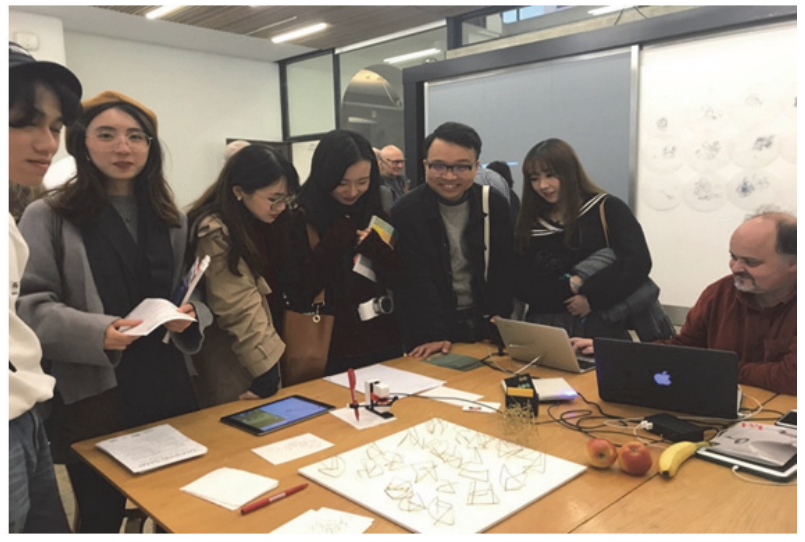

Figure 3: 'The Drawing Machine' - Process on show at V\&A Digital Design Weekend 2018.

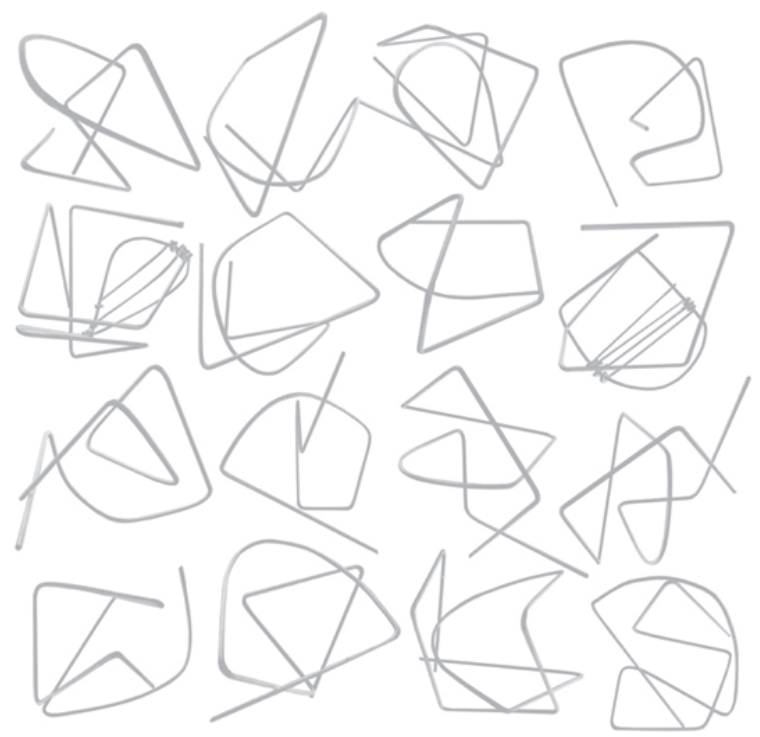

Figure 4: 'Drawing Game' example shapes by Esther Rolinson. 


\section{AN INTERFACE TO EXPLORE DRAWING/LIGHT SEQUENCES}

Rolinson and Clark are now exploring the underlying rules of Rolinson's drawings through the digital drawing tool and it evolving interface. This has allowed for the testing of a diverse range of drawing patterns that relate to a number of different artworks. The interface is presently being enhanced to not only support the capture of drawings, but to simulate light sequences derived from them on-screen. The goal of this work is to enable a fast, iterative drawing process to be used to, initially, simulate lighting sequences and, ultimately, to generate sequences that can be directly fed in to a light-work.

The digital drawing tool has allowed Rolinson to undertake a deeper reflective process during the creation of her latest work. In the work Ignite, she has been able to define a system of movement and light that identifies key light points and the visual rhythms play between them. The analytical process descried above both, responds to, and influences. the hand drawing process. There is potential for a new language of drawing to emerge from this interaction.

\section{USING THIS COMPUTATIONAL DRAWING PROCESS TO INFLUENCE PUBLIC SPACES}

The resulting programming behaviours developed in the experimental process will influence the artworks in the Surgical Centre at Musgrove Park Hospital artworks. It will inform the visual movement language from which lighting and signage will be developed. Rolinson intends to create a delicate 'river system' of light that traverses the hospital spaces. It may potentially be used to direct the flow of people through the complex hospital environment. To do this it essentially needs to be a practical guide, but also strongly influence the atmosphere of the spaces. Rolinson interprets this aspect of the work as a large-scale systematic structure of movement that is spread through a network of buildings. Her intention is to bring sensory connected experience derived from drawings to influence people's movements in this important space.

\section{CONCLUSION}

This project is in its early stages and this paper reports on the work undertaken and shares the insights gained to date. It describes a digital art process that investigates patterns in human behaviours embedded in a hand drawing process. This is being used to influence the subtlety of a network of artworks embedded at the heart of a public space. The work is scheduled to continue over the next three years.

\section{REFERENCES}

Clark, S. and Rolinson, E. (2017) Signal: A Systems-based Creative Collaboration. Proceedings of EVA London, July 2017.

Clark, S. and Scrivener, S. (1993) Using Computers to Capture and Structure Drawing Surface Activity. The First Symposium on Creativity and Cognition. Loughborough, UK.

Rolinson, E. and Clark, S. (2016) 'Flown' Sculptural Light Installation. CHI'2016 Proceedings, San Jose, CA, USA.

Rolinson, E, and Clark, S. (2018a) Digital Structures and Light Movements. Proceedings of EVA London, July 2018.

Rolinson, E. and Clark, S. (2018b) Drawing Game. In Artificially Intelligent. V\&A. 